\title{
Prototipe Sistem Pemantau Kualitas Udara Berbasis Raspberry Pi
}

\author{
Zulhelman ${ }^{1}$, Dwi Arif Wisesa ${ }^{2}$ \\ ${ }^{1,2}$ Program Studi Broadband Multimedia, Jurusan Teknik Elektro, Politeknik Negeri Jakarta \\ JL Prof. Dr. GA Siwabessy, Kampus Baru UI Depok 16425 \\ Email : zulhelman@elektro.pnj.ac.id
}

\begin{abstract}
Abstrak
Particulate Matter (PM) adalah zat polusi udara yang berada di sekitar manusia baik di dalam ruangan maupun di luar ruangan. Manusia tidak dapat melihat ataupun mengetahui kadar partikel polusi di udara serta kualitas udara tanpa alat bantu. Berdasarkan hal tersebut perlu dibuat prototype "Sistem Pemantau Kualitas Udara Berbasis Raspberry Pi". Sistem ini terdiri dari alat yang dapat mengetahui kadar polusi di udara tertutama PM 2.5 dan PM 10 dan untuk mendeteksi kondisi lingkungan sekitarnya seperti suhu, kelembapan, dan tekanan udara. Untuk pendeteksian PM 2.5 dan PM 10 digunakan sensor PMS5003 dan untuk pendeteksian kondisi lingkungan menggunakan sensor SHTC3 (suhu dan kelembapan udara) dan LPS22HB (tekanan udara) yang tersedia dalam modul Sense Hat B. Proses pembacaan menggunakan Raspberry Pi yang diprogram menggunakan Python dan data diproses menjadi Indeks Kualitas Udara berbasis "Indeks Standar Polutan". Dalam penelitian ini dilakukan pengujian spesifikasi input sebagai proses validasi. Hasil pengujian spesifikasi input yang diperoleh menunjukkan kesesuaian antara trend Indeks Kualitas Udara berdasarkan lokasi dan waktu pengambilan data.
\end{abstract}

Keywords: Python, Particulate Matter, PMS5003, Raspberry Pi, Sense Hat B

\begin{abstract}
Particulate Matter (PM) is an air pollutant substance that surrounds humans both indoors and outdoors. Humans cannot see or know the levels of pollution particles in the air and air quality without tools. Based on this, it is necessary to make a prototype "Raspberry Pi-Based Air Quality Monitoring System". This system consists of a tool that can determine the level of pollution in the air, especially PM 2.5 and PM 10 and to detect the surrounding environmental conditions such as temperature, humidity, and air pressure. For the detection of PM 2.5 and PM 10 the PMS5003 sensor is used and for the detection of environmental conditions using the SHTC3 (air temperature and humidity) and LPS22HB (air pressure) sensors which are available in the Sense Hat B module. The reading process uses a Raspberry Pi programmed using Python and data processed into an Air Quality Index based on the "Polutant Standards Index". In this study, the input specification was tested as a validation process. The results of the input specification test obtained indicate a match between the trend of the Air Quality Index based on the location and time of data collection.
\end{abstract}

Keywords: Python, Particulate Matter, PMS5003, Raspberry Pi, Sense Hat B

\section{Pendahuluan}

Particulate Matter adalah zat polusi udara yang berada di sekitar manusia baik di dalam ruangan maupun di luar ruangan. Zat polusi ini berasal dari aktifitas sehari-hari manusia seperti memasak, berkendara, material banguan sekitar, hingga kegiatan perekonomian seperti industri dan pembangunan [1]. Paparan particulate matter yang tinggi pada manusia dapat menyebabkan dampak kesehatan yang buruk. Dampak kesehatan yang sering terjadi adalah meningkatnya resiko kematian yang disebabkan oleh penyakit paru-paru obstruktif, penyakit kardiovaskular, dan hipertensi [2]. Dalam praktiknya, kadar polutan di udara sekitar tidak dapat dilihat dengan mata telanjang oleh manusia, namun dapat dideteksi dengan menggunakan sensor yang mendeteksi kadar partikel polutan yang berada di udara. Sistem pemantau kualitas udara ini terdiri dari beberapa sensor yang mampu mengetahui parameterparameter di lingkungan sekitar seperti jumlah kadar zat partikel polusi yang ada di udara, serta data tambahan pada lingkungan tersebut seperti suhu, tekanan udara, dan kelembapan udara. 
Pembuatan prototype sistem ini bertujuan untuk mengembangkan alat serupa yang telah ada. Alat berbentuk prototipe "Sistem Pemantauan Kualitas Udara Berbasis Raspberry Pi”. Sistem ini terdiri dari sebuah alat yang dapat mengetahui tingkat pencemaran di udara khususnya PM 2.5 dan PM 10 serta untuk mendeteksi kondisi lingkungan sekitar seperti suhu, kelembaban, dan tekanan udara. Untuk pendeteksian PM 2.5 dan PM 10 digunakan sensor PMS5003 dan untuk pendeteksian kondisi lingkungan menggunakan sensor SHTC3 (suhu dan kelembaban udara) dan LPS22HB (tekanan udara) yang tersedia pada modul Sense Hat B. Proses pembacaan menggunakan Raspberry $\mathrm{Pi}$ yang diprogram menggunakan Python dan data diolah menjadi Air Quality Index berdasarkan "Polutant Standards Index". Dalam penelitian ini, spesifikasi input diuji, digunakan pada proses validasi. Hasil pengujian spesifikasi input yang diperoleh menunjukkan adanya kesesuaian antara trend Indeks Kualitas Udara berdasarkan lokasi dan waktu pengambilan data. juga dapat mengukur parameter-parameter tersebut, namun memiliki kelemahan yaitu data yang didapatkan hanya dapat dilihat secara lokal.

Tujuan dalam penelitian ini adalah merancang dan membuat sistem pemantau kualitas udara berbasis Raspberry $\mathrm{Pi}$, yang dapat menyajikan data dari sensor pada dashboard di dalam Platform IoT. Data yang telah disajikan tersebut dapat diakses oleh pengguna secara remote, dan menganalisis performa sistem pemantau kualitas udara tersebut.

\section{Metode Penelitian}

\section{A. Dasar Teori}

1. Particulate Matter adalah materi yang berada di udara dan berukuran kecil sehingga tidak dapat dilihat oleh kasat mata. Partikel ini berasal dari hasil pembakaran bahan bakar yang berbasis karbon, debu-debu yang berada di udara, pembakaran batu-bara, industri dan kegiatan rumah tangga [3]. Penentuan indeks kualitas udara ditentukan berdasarkan jumlah konsentrasi PM 2.5 dan PM 10 di udara dengan waktu pengukuran rata-rata sebanyak 24 Jam.

Pada umumnya, nilai PM di suatu lokasi memiliki trend siklus tertinggi setiap pagi hari saat lalu-lintas padat dan pada malam hari menjelang tengah malam serta memiliki trend siklus terendah pada siang hingga sore hari [4]. Tabel 1 memperlihatkan ambang batas Indeks Kualitas Udara.
2. Python

Python adalah bahasa pemograman tingkat tinggi yang dibuat oleh Guido van Rossum pada tahun 1991. Python menawarkan fitur kompilasi bahasa yang lebih cepat dan fleksibel, juga dikenal sebagai bahasa yang mudah dipelajari. Selain itu Python bersifat open-source sehingga bebas digunakan dan didistribusikan baik untuk penggunaan pendidikan, maupun komersial [5].

3. Raspberry Pi

Raspberry Pi adalah komputer berbentuk mini yang seukuran dengan kartu kredit yang dapat digunakan sebagai perangkat komputer biasa maupun perangkat IoT. Raspberry Pi diluncurkan oleh Raspberry Pi Foundation yang bertujuan untuk mengenalkan dan memberi pengertian bagaimana sistem komputer itu bekerja. Raspberry Pi umumnya digunakan pada proyek berbasis komputasi dan IoT.

4. PMS5003

PMS5003 adalah sensor pendeteksi PM yang berada di udara. Sensor ini bekerja dengan bantuan laser yang memberikan output digital dari konsentrasi banyaknya partikel di udara. Sensor ini dapat mendeteksi partikel yang berdiameter mulai dari $0.3 \mu \mathrm{m}$ hingga $10 \mu \mathrm{m}$. Dalam penggunaannya sensor ini dapat mendeteksi PM 2.5 dan PM 10 [6].

\section{HTTP}

HTTP adalah protokol umum yang digunakan untuk komunikasi antara browser, server, dan aplikasi web lainnya melalui TCP/IP. HTTP bersifat reliable yang menjamin bawha data tidak akan rusak atau terpotong di tengah kanal informasi. Pada praktik penggunaannya, HTTP dignakan antara client dengan web server yang dituju [7].

6. Sense Hat B

Sense Hat B adalah modul atau HAT yang memiliki beberapa fungsi dan sensor didalamnya. Pada Sense Hat B memiliki sensor seperti sensor gerak (ICM20948), sensor suhu dan kelembapan udara (SHTC3), sensor tekanan udara (LPS22HB), sensor warna (TCS34725), dan 4 kanal Analog to Digital Converter (ADC) 12 bit untuk ekspansi sensor lainnya [8]. 
Tabel 1. Ambang Batas Indeks Kualitas Udara (ISPU Kementrian Lingkungan Hidup dan Kehutanan)

\begin{tabular}{|c|c|c|c|c|}
\hline \multirow{2}{*}{ Indeks } & \multicolumn{2}{|c|}{ Ambang Batas } & \multirow{2}{*}{ Keterangan } & \multirow{2}{*}{ Kode Warna } \\
\hline & $\begin{array}{l}\text { PM 2.5 } \\
\left(\mu \mathrm{g} / \mathrm{m}^{3}\right)\end{array}$ & $\begin{array}{l}\text { PM 10 } \\
\left(\mu \mathrm{g} / \mathbf{m}^{3}\right)\end{array}$ & & \\
\hline $0-50$ & $0,0-12$ & $0-55$ & Baik & Hijau \\
\hline $51-100$ & $12,1-35$ & $55,1-155$ & Sedang & Kuning \\
\hline $101-150$ & $35,1-55,0$ & $155,1-255$ & $\begin{array}{c}\text { Tidak Sehat } \\
\text { (Untuk Golongan Sensitif) }\end{array}$ & Oranye \\
\hline $151-200$ & $55,1-150,0$ & $255,1-355$ & Tidak Sehat & Merah \\
\hline $201-300$ & $150,1-250$ & $355,1-425$ & Sangat Tidak Sehat & Ungu \\
\hline $301-500$ & $>250$ & $>425$ & Berbahaya & Merah Maroon \\
\hline
\end{tabular}

7. Ubidots

Ubidots adalah Platform IoT yang digunakan untuk mengirim data ke cloud dari perangkat yang terhubung ke internet. Pengguna dapat mengatur aksi dan notifikasi berdasarkan data realtime [9]. Ubidots menawarkan REST API yang mengizinkan pengguna untuk membaca dan menulis data ke dalam resource yang ada seperti variabel, nilai, event, dan lain-lain. API juga mendukung HTTP dan HTTPS dan membutuhkan API Key untuk membaca dan menulis data tersebut [10].

8. ISO/IEC 25010

ISO/IEC 25010 adalah standar tolak ukur analisis kualitas perangkat lunak yang digunakan oleh perusahaan, instansi ataupun organisasi. Standar internasional ini digunakan untuk menguji sistem informasi yang akan digunakan [11].

\section{B. Perancangan dan Realisasi}

Langkah-langkah dalam perancangan dan realisasi sistem adalah :

1. Perancangan Alat Sistem Pemantau Kualitas Udara Berbasis Raspberry Pi yang terdiri dari sensor kualitas udara PMS5003, dan sensor yang mendeteksi kondisi lingkungan sekitar yaitu LPS22HB dan SHTC3.

2. Pemrograman Python pembacaan nilai sensor yang ditanam dalam Raspberry Pi.

3. Pengujian Alat dilakukan di dua lokasi dan kualitas udara yang berbeda dan waktu pengambilan data yang berbeda untuk melihat kesesuaian dengan trend kualitas udara di tempat tersebut yang dibandingkan dengan Indeks Standar Pencemaran Udara (ISPU) Kementrian Lingkungan Hidup dan Kehutanan.
Gambar 2 menunjukan Flowchart Program yang dibuat :

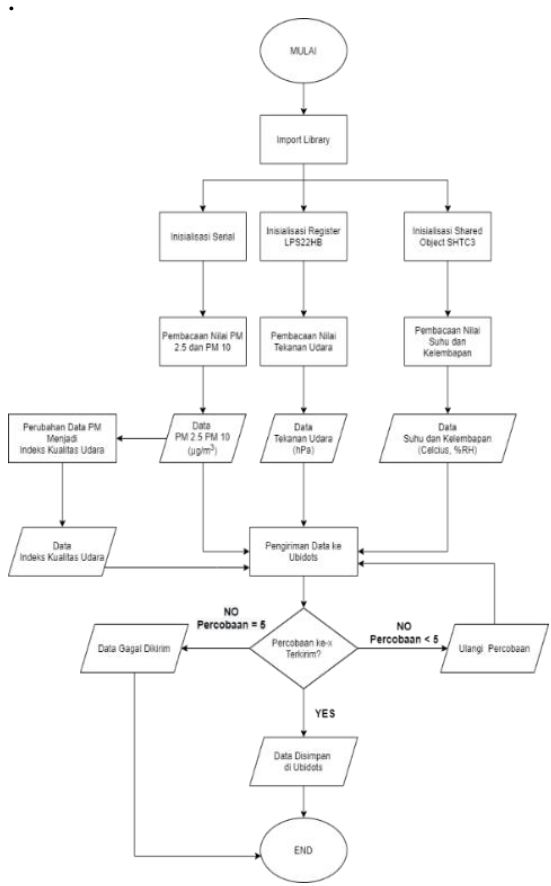

Gambar 2 : Flowchart Program Pada Raspberry Pi

\section{Hasil dan Pembahasan}

Rangkaian Pengujian dapat dilihat pada Gambar 3.

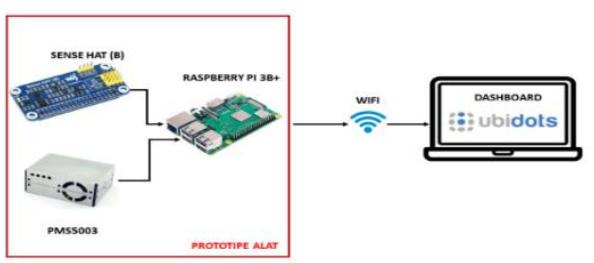

Gambar 3. Rangkaian Pengujian Spesifikasi Input Partikel Polusi Udara 
Gambar 3, memperlihatkan bahwa spesifikasi input diperoleh dari hasil sensor Hat B dan PM 55003.

\section{A. Hasil Pengujian Spesifikasi Input Partikel Polusi Udara}

Pengujian spesifikasi input Partikel Polusi Udara ini ditujukan untuk mengetahui kesesuaian data hasil alat pendeteksian yang dilakukan di dua lokasi yang berbeda dengan waktu yang berbeda. Pengujian ini dilakukan dengan pengambilan data selama 24 jam dengan interval waktu setiap 1 jam pada dua lokasi tersebut, serta pada lokasi dengan kondisi tertentu. Waktu pengambilan data pagi hari dan siang hari, pengujian dilakukan di Taman Narogong Indah, Rawalumbu, Kota Bekasi (TNI), Pondok Mitra Lestari, Jakasetia, Kota Bekasi (PML) yang berjarak 5 $\mathrm{km}$. Tabel 2 memperlihatkan hasil pengujian spesifikasi input alat yang dibuat dengan sensor PMS5003 selama 24 jam. Pada pengujian selama 24 jam, terlihat ada kesesuaian trend konsentrasi partikel PM 2.5 dan PM 10 yaitu meningkat di malam hingga pagi hari, dan menurun di siang hingga sore hari. Hal ini diperkuat dengan pengujian dalam kondisi lingkungan pada waktu tertentu yaitu pada pagi dan siang hari dalam karakteristik lokasi yang berbeda perubahan jumlah partikel polusi udara pengaruh lokasi pengambilan data. maka dapat disimpulkan spesifikasi Input Partikel Polusi Udara meningkat ketika malam hingga pagi hari dan menurun ketika siang hingga sore hari.

\section{B. Hasil Pengujian Spesifikasi Input Suhu dan Kelembapan}

Pengujian spesifikasi input Suhu dan Kelembapan juga ditujukan untuk mengetahui kesesuaian pendeteksian alat dengan mengukur di dua lokasi yang berbeda dengan waktu yang berbeda. Pengujian ini melakukan Pengambilan data diambil sebanyak 24 jam dengan interval waktu 1 jam pada dua lokasi berbeda, serta pada lokasi tertentu dengan waktu pengambilan data pagi hari dan siang hari. Data dapat dilihat pada Tabel 3 dan Tabel 4 .

Tabel 4 memperihatkan trend pengukuran nilai kelembapan udara memiliki korelasi negatif terhadap suhu. Untuk pengujian di siang hari nilai suhu lebih tinggi dan kelembapan lebih rendah dibandingkan dengan pengujian di pagi hari. Sedangkan, spesifikasi input suhu udara mampu mendeteksi perbedaan suhu. Dapat disimpulkan bahwa spesifikasi input suhu dan kelembapan sudah berjalan dengan baik.
Tabel 2 Pengujian Spesifikasi Input Partikel Polusi Udara

\begin{tabular}{lccc|cc}
\hline \multirow{2}{*}{ Pengujian } & Jam & \multicolumn{2}{c}{$\begin{array}{c}\text { PM2.5 } \\
\left(\boldsymbol{\mu g} / \mathbf{m}^{\mathbf{3}}\right)\end{array}$} & \multicolumn{2}{c}{$\begin{array}{c}\text { PM10 } \\
\left(\boldsymbol{\mu g} / \mathbf{m}^{\mathbf{3}}\right)\end{array}$} \\
\cline { 3 - 6 } & & TNI & PML & TNI & PML \\
\hline 1 & $0: 00$ & 67 & 72 & 75 & 78 \\
2 & $1: 00$ & 245 & 66 & 258 & 77 \\
3 & $2: 00$ & 201 & 51 & 215 & 65 \\
4 & $3: 00$ & 195 & 58 & 209 & 73 \\
5 & $4: 00$ & 227 & 70 & 254 & 77 \\
6 & $5: 00$ & 188 & 57 & 215 & 71 \\
7 & $6: 00$ & 186 & 122 & 206 & 133 \\
8 & $7: 00$ & 191 & 90 & 204 & 95 \\
9 & $8: 00$ & 209 & 114 & 231 & 127 \\
10 & $9: 00$ & 187 & 95 & 198 & 109 \\
11 & $10: 00$ & 90 & 77 & 99 & 87 \\
12 & $11: 00$ & 114 & 46 & 122 & 56 \\
13 & $12: 00$ & 126 & 41 & 137 & 50 \\
14 & $13: 00$ & 139 & 88 & 149 & 96 \\
15 & $14: 00$ & 102 & 80 & 106 & 89 \\
16 & $15: 00$ & 83 & 40 & 89 & 76 \\
17 & $16: 00$ & 91 & 55 & 100 & 71 \\
18 & $17: 00$ & 52 & 73 & 65 & 78 \\
19 & $18: 00$ & 62 & 73 & 73 & 81 \\
20 & $19: 00$ & 103 & 80 & 113 & 94 \\
21 & $20: 00$ & 178 & 88 & 190 & 96 \\
22 & $21: 00$ & 184 & 90 & 201 & 64 \\
23 & $22: 00$ & 224 & 49 & 247 & 77 \\
24 & $23: 00$ & 199 & 136 & 219 & 152 \\
Rata-Rata & $\mathbf{1 5 1 . 9 6}$ & $\mathbf{7 5 . 4 9}$ & $\mathbf{1 6 5 . 6 3}$ & $\mathbf{8 6 . 3 4}$ \\
\hline & & & & &
\end{tabular}

Tabel 3 Data Hasil Pengujian Spesifikasi Input Suhu 24 Jam

\begin{tabular}{cccc}
\hline Pengujian & Jam & $\begin{array}{c}\text { Suhu }\left({ }^{\circ} \mathbf{C}\right) \\
\text { Lokasi : TNI }\end{array}$ & $\begin{array}{c}\text { Suhu }\left({ }^{\circ} \mathbf{C}\right) \\
\text { Lokasi : PML }\end{array}$ \\
\hline 1 & $0: 00$ & 32,36 & 29,06 \\
2 & $1: 00$ & 31,98 & 28,79 \\
3 & $2: 00$ & 31,32 & 28,55 \\
4 & $3: 00$ & 30,66 & 28,73 \\
5 & $4: 00$ & 30,27 & 28,75 \\
6 & $5: 00$ & 30,24 & 29,12 \\
7 & $6: 00$ & 29,87 & 28,75 \\
8 & $7: 00$ & 29,58 & 28,51 \\
9 & $8: 00$ & 29,49 & 28,68 \\
10 & $9: 00$ & 29,65 & 30,28 \\
11 & $10: 00$ & 31,18 & 34,50 \\
12 & $11: 00$ & 31,66 & 34,28 \\
13 & $12: 00$ & 32,20 & 36,04 \\
14 & $13: 00$ & 32,84 & 36,99 \\
15 & $14: 00$ & 33,06 & 36,12 \\
16 & $15: 00$ & 33,71 & 35,86 \\
17 & $16: 00$ & 33,78 & 34,97 \\
18 & $17: 00$ & 32,13 & 35,10 \\
19 & $18: 00$ & 31,82 & 35,20 \\
20 & $19: 00$ & 32,05 & 34,70 \\
21 & $20: 00$ & 31,98 & 33,29 \\
22 & $21: 00$ & 31,75 & 33,31 \\
23 & $22: 00$ & 31,30 & 32,78 \\
24 & $23: 00$ & 30,58 & 30,23 \\
\hline
\end{tabular}


Tabel 4 Data Hasil Pengujian Spesifikasi Input Kelembapan 24 Jam

\begin{tabular}{cccc}
\hline Pengujian & Jam & $\begin{array}{c}\text { Kelembapan } \\
\text { (\% RH) } \\
\text { Lokasi : } \\
\text { TNI }\end{array}$ & $\begin{array}{c}\text { Kelembapan } \\
\text { (\% RH) } \\
\text { Lokasi : } \\
\text { PML }\end{array}$ \\
\hline 1 & $0: 00$ & 70,74 & 78,59 \\
2 & $1: 00$ & 68,63 & 78,85 \\
3 & $2: 00$ & 70,55 & 79,17 \\
4 & $3: 00$ & 65,80 & 78,12 \\
5 & $4: 00$ & 68,14 & 76,41 \\
6 & $5: 00$ & 67,91 & 76,05 \\
7 & $6: 00$ & 69,68 & 76,38 \\
8 & $7: 00$ & 71,34 & 79,02 \\
9 & $8: 00$ & 72,62 & 77,89 \\
10 & $9: 00$ & 71,11 & 72,61 \\
11 & $10: 00$ & 68,02 & 60,36 \\
12 & $11: 00$ & 67,37 & 58,74 \\
13 & $12: 00$ & 65,87 & 54,22 \\
14 & $13: 00$ & 61,56 & 46,79 \\
15 & $14: 00$ & 65,47 & 50,23 \\
16 & $15: 00$ & 61,72 & 56,64 \\
17 & $16: 00$ & 61,58 & 59,48 \\
18 & $17: 00$ & 58,56 & 52,65 \\
19 & $18: 00$ & 57,85 & 57,04 \\
20 & $19: 00$ & 61,46 & 60,21 \\
21 & $20: 00$ & 62,89 & 63,51 \\
22 & $21: 00$ & 69,33 & 61,85 \\
23 & $22: 00$ & 74,30 & 62,61 \\
24 & $23: 00$ & 75,21 & 72,60 \\
\hline & & &
\end{tabular}

\section{Pengujian Spesifkasi Input Tekanan Udara}

Tabel 5 memperlihatkan Data Hasil Pengujian Spesifikasi Input Tekanan Udara, dimana terdapat sedikit perbedaan nilai pengukuran tekanan udara, dan cenderung stabil dalam waktu pengujian tertentu. Sehingga dapat disimpulkan pengukuran tekanan udara di kedua lokasi pengukuran menunjukkan spesifikasi input tekanan udara sudah sesuai.

Tabel 5 Data Hasil Pengujian Spesifikasi Input Tekanan Udara Waktu Pengambilan 24 Jam

\begin{tabular}{ccc}
\hline Jam & $\begin{array}{c}\text { Tekanan } \\
\text { Udara (mbar) } \\
\text { Lokasi :TNI }\end{array}$ & $\begin{array}{c}\text { Tekanan Udara } \\
\text { (mbar) } \\
\text { Lokasi : PML }\end{array}$ \\
\hline $0: 00$ & 1012 & 1011 \\
1:00 & 1012 & 1011 \\
$2: 00$ & 1012 & 1011
\end{tabular}

\begin{tabular}{ccc}
$3: 00$ & 1011 & 1010 \\
$4: 00$ & 1011 & 1010 \\
$5: 00$ & 1011 & 1009 \\
$6: 00$ & 1011 & 1010 \\
$7: 00$ & 1012 & 1010 \\
$8: 00$ & 1012 & 1010 \\
$9: 00$ & 1013 & 1010 \\
$10: 00$ & $10: 00$ & $10: 00$ \\
$11: 00$ & $11: 00$ & $11: 00$ \\
$12: 00$ & $12: 00$ & $12: 00$ \\
$13: 00$ & $13: 00$ & $13: 00$ \\
$14: 00$ & $14: 00$ & $14: 00$ \\
$15: 00$ & $15: 00$ & $15: 00$ \\
$16: 00$ & $16: 00$ & $16: 00$ \\
$17: 00$ & $17: 00$ & $17: 00$ \\
$18: 00$ & $18: 00$ & $18: 00$ \\
$19: 00$ & $19: 00$ & $19: 00$ \\
$20: 00$ & $20: 00$ & $20: 00$ \\
$18: 00$ & $18: 00$ & $18: 00$ \\
$19: 00$ & $19: 00$ & $19: 00$ \\
$20: 00$ & $20: 00$ & $20: 00$ \\
$18: 00$ & $18: 00$ & $18: 00$ \\
$19: 00$ & $19: 00$ & $19: 00$ \\
$20: 00$ & $20: 00$ & $20: 00$ \\
$21: 00$ & $21: 00$ & $21: 00$ \\
$22: 00$ & $22: 00$ & $22: 00$ \\
$23: 00$ & $23: 00$ & $23: 00$ \\
\hline
\end{tabular}

\section{Pengujian Pendeteksian Indeks Kualitas Udara}

Pengujian pendeteksian Indeks Kualitas Udara dilakukan berdasarkan perbedaan karakteristik lokasi dalam kondisi pengukuran waktu yang sama. Tabel 6 adalah data hasil pengujian pendeteksian indeks kualitas udara berdasarkan pengujian tersebut dapat disimpulkan bahwa kualitas udara pada siang hari lebih baik daripada kualitas udara pada pagi hari dengan jenis polutan utama adalah PM 2.5. Sedangkan untuk lokasi pengujian pada siang hari terlihat pada kawasan industri sedikit lebih buruk dan pada pagi hari terlihat pada perkampungan sedikit lebih buruk. Maka dapat disimpulkan bahwa kinerja alat atas pendeteksian indeks kualitas udara dengan Standar Polutan Index sudah berjalan dengan baik dan sesuai. 
Tabel 6 Data Hasil Pengujian Indeks Kualitas Udara

\begin{tabular}{|c|c|c|c|c|c|}
\hline Lokasi & Waktu & $\begin{array}{c}\text { Rata-Rata } \\
\text { AQI } 2.5\end{array}$ & Keterangan & $\begin{array}{c}\text { Rata-Rata } \\
\text { AQI } 10\end{array}$ & Keterangan \\
\hline MM2100 & Siang & 120,17 & $\begin{array}{l}\text { Tidak Sehat Untuk } \\
\text { Golongan Sensitif }\end{array}$ & 48 & Baik \\
\hline GW & Siang & 108,17 & $\begin{array}{l}\text { Tidak Sehat Untuk } \\
\text { Golongan Sensitif }\end{array}$ & 41,17 & Baik \\
\hline Makrik & Pagi & 218,84 & Sangat Tidak Sehat & 118,83 & $\begin{array}{l}\text { Tidak Sehat Untuk } \\
\text { Golongan Sensitif }\end{array}$ \\
\hline Cipendawa & Pagi & 211,5 & Sangat Tidak Sehat & 85,34 & Sedang \\
\hline
\end{tabular}

\section{Kesimpulan}

a. Pada pengujian spesifikasi input partikel polusi udara, pengukuran PM 2.5 dan PM 10 terbukti mengikuti trend yang ada yaitu perubahan jumlah partikel polusi udara meningkat ketika malam hingga pagi hari dan menurun ketika siang hingga sore hari. Maka dapat disimpulkan spesifikasi input partikel polusi udara tersebut sudah berjalan dengan baik

b. Pada pengujian spesifikasi input suhu dan kelembapan udara terlihat bahwa spesifikasi input suhu dan kelembapan udara mampu mendeteksi perbedaan suhu dan kelembapan udara dengan hubungan kelembapan udara memiliki korelasi negatif terhadap suhu. Maka dapat disimpulkan bahwa spesifikasi input suhu dan kelembapan sudah berjalan dengan baik.

c. Pada pengujian spesifikasi input tekanan udara terlihat bahwa spesifikasi input tekanan udara mampu mendeteksi sedikit perbedaan tekanan udara di lokasi sekitar pengukuran. Maka dapat disimpulkan bahwa spesifikasi input tekanan udara sudah berjalan dengan baik

d. Pada pengujian pendeteksian indeks kualitas udara dapat disimpulkan bahwa kinerja alat atas pendeteksian indeks kualitas udara dengan Standar Polutan Index yang digunakan oleh Kementerian Lingkungan Hidup dan Kehutanan (KLHK).

\section{Daftar Acuan}

[1] R. M. Harrison, Airborne particulate matter. Philosophical Transacttion Of The Royal Society A. (2020).

[2] Y. A. Alemayehu, S. L. Asfaw, T. A. Terfie, Exposure to urban particulate matter and its association with human health risks.
Environmental Science and Pollution Research, 27(22), 27491-27506 (2020).

[3] R. Zhang, dkk, Formation of Urban Fine Particulate Matter. Chemical Reviews, 115(10), 3803-3855 (2015).

[4] I. R. J. Sari, dkk, Prosiding SNST, Pola Sebaran Polutan PM 2.5 dan PM 10 Harian Terhadap Faktor Suhu dan Kelembaban, 2019, p. 95-100.

[5] A. Downey, Think Python - How to Think Like a Computer Scientist, Green Tea Press, 2012.

[6] Anon, Plantower, Plantower PMS5003 Data Manual, 2016.

[7] A. J. Nathan, A. Scobell, HTTP Guide. Foreign Affairs, 2012.

[8] Waveshare. (n.d.). Sense Hat (B) Waveshare Wiki. https://www.waveshare.com/wiki/Sense_HAT_(B )

[9] R. Teguh, E. D. Oktaviyani, K. A. Mempun, Rancang Bangun Desain Internet of Things Untuk Pemantauan Kualitas Udara Pada Studi Kasus Polusi Udara, Jurnal Teknologi Informasi Jurnal Keilmuan Dan Aplikasi Bidang Teknik Informatika, 2018, 12(2), p. 47-58.

[10] Z. Muhammad, dkk, Smart Agriculture Using Internet of Things with Raspberry Pi, Proceedings - 10th IEEE International Conference on Control System, Computing and Engineering (ICCSCE), 2020, August, p. 85-90. 